\title{
O GÊNERO CHRYSOPHYLLUM L. (SAPOTACEAE) NO SEMIÁRIDO
}

\author{
$\underline{\text { Rísia Cean Silva de Lima Santos }}{ }^{1}$; Cláudia Elena Carneiro ${ }^{2}$ \\ 1. Bolsista PIBIC/Fapesb, Graduando em Ciências Biológicas, Universidade Estadual de Feira de Santana, e-mail: \\ risiacean.s@gmail.com \\ 2. Orientador, Departamento de Ciências Biológicas, Universidade Estadual de Feira de Santana, e-mail: \\ cecarneiro@gmail.com
}

PALAVRAS-CHAVE: morfologia; taxonomia; florística

\section{INTRODUÇÃO}

O Semiárido brasileiro está concentrado no Nordeste do Brasil. Apresenta a mais diversa dentre as paisagens brasileiras, tanto em relação a geomorfologia quanto aos tipos de vegetações. Esta diversidade ambiental se reflete na maior biodiversidade, na taxonomia complicada dos grupos e em padrões biogeográficos complexos em escalas relativamente pequenas. A totalidade dos acervos do Nordeste representa uma coleção de inestimável valor da flora do Semiárido brasileiro, pois a maior parte dessas amostras provém desta região, com destaque para as plantas da caatinga, das florestas estacionais, do cerrado e dos campos rupestres (Queiroz et al, 2006). O Nordeste e especialmente o Bioma das Caatingas, totalmente incluído no Semiárido, tem sido considerado como o bioma mais pobre em biodiversidade do Brasil. Dentre as inúmeras famílias que compõem a flora do Semiárido, Sapotaceae ocupa lugar de destaque em ambientes florestais, representada por árvores e arbustos reconhecidos facilmente pela combinação do látex com o arranjo e venação das folhas (Gentry 1993). Dos 12 gêneros e 232 espécies ocorrentes no Brasil, atualmente não há estimativa do número de espécies de Sapotaceae que ocorrem no semiárido, inclusive para o gênero Chrysophyllum L. (Carneiro et al. 2017). A falta de informações básicas sobre a caracterização dos ecossistemas do Nordeste, sua biodiversidade e a potencialidade dos seus recursos naturais, gera um atraso científico e tecnológico em relação às outras regiões do país, sendo assim o objetivo deste trabalho é levantar, identificar e descrever as espécies de Chrysophyllum L. ocorrentes no semiárido. A justificativa para tal consideração seria a presença de uma vegetação derivada de outras formações vegetais modificadas, altamente antropizada e sem espécies endêmicas (Edital MCT/CNPQ/PPBIO, 2010). Assim, a busca de detalhes torna-se essencial para o entendimento do organismo que vive em diversos ecossistemas, fornecendo vários produtos, que no conjunto propiciarão uma melhoria do conhecimento disponível sobre a flora do semiárido, incluindo sua identificação, utilização e conservação.

\section{MATERIAL E MÉTODOS OU METODOLOGIA (ou equivalente)}

Os métodos incluem: Levantamento e identificação dos táxons através de consulta a herbário e bibliografia específica; Coleta de material botânico em campo e em herbário; Processamento das amostras utilizando técnicas comumente empregadas em estudos morfológicos e taxonômicos; Realização de testes histoquímicos para identificação de compostos químicos específicos dos componentes celulares, tais como amido, celulose, lignina, tanino, composto fenólicos, cristais, entre outros (Johansen 1940; Kraus \& Arduin 1997; Macêdo 1997); Montagem de lâminas histológicas para análises, utilizando meios de montagem semi-permanentes e permanentes; Análise morfológica e histoquímica, culminando na descrição dos produtos; Fotomicrografia dos táxons, destacando os caracteres mais significativos. 


\section{RESULTADOS E/OU DISCUSSÃO (ou Análise e discussão dos resultados)}

O gênero Chrysophyllum L. está representado no semiárido por cinco espécies (Chrysophyllum arenarium Allemão, Chrysophyllum gonocarpum (Mart. \& Eichler ex Miq.) Engl., Chrysophyllum marginatum (Hook. \& Arn.), Chrysophyllum rufum Mart. e Chrysophyllum splendens Spreng). Foram analisadas quatro espécies, pois devido a dificuldades encontradas para coletar, e a dúvida sobre a identificação correta nos locais em que se encontram, o material da espécie $C$. arenarium não foi possível realizar a caracterização desta. A caracterização anatômica das folhas das quatro espécies estudadas é apresentada a seguir, conforme as regiões analisadas, na seguinte ordem: lâmina foliar (epiderme, mesofilo e feixe vascular) e pecíolo.

\section{Lâmina foliar - Epiderme}

Em vista frontal, as epidermes das espécies apresentaram características distintas, variando o formato e contorno das células epidérmicas, ornamentação na cutícula, presença e tipo de estômatos, e presença de cicatrizes de tricomas. O formato das células epidérmicas variou de retangular a poligonal e a parede anticlinal, de reta a sinuosa, com grau de sinuosidade variável. Em C. gonocarpum (BA) e C. marginatum as células são retangulares com paredes anticlinais com alto grau de sinuosidade. Os espécimes de $C$. gonocarpum e $C$. splendens coletados no estado de Pernambuco apresentaram células intercostais de formato retangular com paredes anticlinais sinuosas, e células costais também retangulares com paredes anticlinais levemente sinuosas. Em $C$. rufum e $C$. splendens (BA), as células intercostais são de formato poligonal com paredes anticlinais muito sinuosas, e as células costais também poligonais com paredes anticlinais sinuosas. Não houve variação nos espécimes analisados, mantendo as mesmas características para cada uma das espécies. As folhas apresentam tricomas tectores do tipo malpighiáceo. O espécime de C. gonocarpum coletado na Bahia foi o único espécime desprovido de tricomas, diferentemente do espécime coletado no Pernambuco, que apresenta tricomas nas duas faces da folha. De acordo com a distribuição dos estômatos nas faces das folhas, as quatros espécies foram classificadas como hipoestomáticas, exceto o espécime de $C$. gonocarpum (PE) que contem estômatos nas duas superfícies foliares, caracterizando-a como anfiestomática. Os estômatos variam entre anisocíticos (C. marginatum, $C$. rufum, $C$. splendens) que também foi identificado no espécime de $C$. gonocarpum (PE) e paracítico em $\mathrm{C}$. gonocarpum (BA) e C. splendens (PE), sendo o tipo anisocítico predominante dentre as espécies analisadas. No espécime de C. gonocarpum (PE) foi possível observar a presença dos estômatos apenas sobre a nervura principal. Em seção transversal, as epidermes de todas das espécies estudadas são unisseriadas. A epiderme apresenta uma cutícula, que é uma camada separada de uma substância graxa complexa (Appezzatoda-Glória \& Carmello-Guerreiro, 2013), dentre as espécies descritas apenas $C$. marginatum apresentou estas ornamentações, em sua face adaxial.

\section{Lâmina foliar - Mesofilo}

Todas as espécies de Chrysophyllum L. apresentaram o mesofilo dorsiventral, como descrito por Metcalfe \& Chalk (1972), composto por estratos de parênquima paliçádico (1-2), e parênquima esponjoso que podem apresentar até 07 estratos, com muitos espaços intercelulares com distribuição irregular. Os espécimes de $C$. gonocarpum (PE) e de $C$. splendens (PE) apresenta células de colênquima subepidérmico abaixo das células de epiderme, desde o feixe vascular se estendendo até o bordo da folha. $\mathrm{O}$ bordo das espécies analisadas está caracterizado levemente fletido (os dois espécimes de $C$. gonocarpum, $C$. marginatum) e fortemente fletido $(C$. rufum) e não fletido $(C$. splendens (BA) e C. splendens (PE)). As células do parênquima paliçádico mudam sua conformação ao se aproximar da região distal do bordo, passando de retangular para arredondadas, tornando-se menores e mais numerosas. Nessa região da lâmina foliar, a 
cutícula das folhas de Chysophyllum L., que se encontram especialmente na face abaxial (Metcalfe \& Chalk, 1972) apresentam ornamentações, chamadas flanges, em todas as espécies.

\section{Lâmina foliar - Feixe Vascular}

Em seção transversal, a nervura principal das folhas apresentou feixe vascular único, com variações na conformação da medula central circundado por fibras de esclerênquima. Das quatro espécies de Chrysophyllum L. que foram analisadas, o espécime C. gonocarpum (BA) apresentou sistema vascular em arco aberto, $C$. splendens (PE) tem sistema vascular côncavo-convexo, enquanto $C$. marginatum e $C$. rufum tem sistema vascular plano-convexo e o espécime $C$. gonocarpum (PE) apresenta sistema vascular em arco fechado, todos os feixes vasculares são circundados por fibras de esclerênquima. Segundo Pennington (1990) Chrysophyllum L. apresenta venação broquidódroma ou eucamptódroma. Das quatro espécies estudadas, foram encontrados cristais monoprismáticos em C. marginatum, C. gonocarpum (PE), C. splendens (PE). A presença de monocristais prismáticos, na epiderme, configura um caráter confiável, quando combinado com outros caracteres (Metcalfe \& Chalk, 1979).

Pecíolo - Em secção transversal, o pecíolo das espécies de Chrysophyllum L. apresentou padrão correspondente a plano-convexo (C. gonocarpum (PE), C. splendens (BA) $e$. rufum) e côncavo-convexo (C. gonocarpum (BA), C. marginatum, C. splendens (PE)), além do cinturão de células esclerenquimáticas em volta do feixe central. Todas as espécies possuem sistema colateral, no qual o floema está voltado para a periferia do órgão e o xilema para o centro. A epiderme é uniestratificada em todas as espécies, com células de paredes retas, revestida por uma camada de cutícula pouco espessa. Abaixo da camada de células epidérmicas são encontradas células de colênquima, seguidas de parênquima de preenchimento. O feixe vascular possui medula parenquimática, e é circundado por fibras esclerenquimáticas como foi registrado por Solereder (1908). Com os resultados foi elaborada uma tabela com os caracteres morfoanatômicos das espécies:

Tabela : Características anatômicas das folhas de quatro espécies de Chrysophyllum $\mathrm{L}$. (Sapotaceae) ocorrentes no semiárido.

\begin{tabular}{l|c|c|c|c|c|c} 
& \multicolumn{5}{c}{ Espécies } \\
\cline { 2 - 7 } Caracteres & $\mathbf{1 a}$ & $\mathbf{1 b}$ & $\mathbf{2}$ & $\mathbf{3}$ & $\mathbf{4 a}$ & $\mathbf{4 b}$ \\
\hline Paredes anticlinais retas & - & - & - & + & - & - \\
\hline Paredes anticlinais sinuosas & + & + & + & + & + & + \\
\hline Estômato anomocítico & - & - & - & - & - & - \\
\hline Estômato anisocítico & - & + & + & + & + & - \\
\hline Estômato paracítico & + & + & - & - & - & + \\
\hline Mesofilo dorsiventral & + & + & + & + & + & + \\
\hline Números de camadas da epiderme & I & I & I & I & I & I \\
\hline Número de camadas de parênquima paliçádico & II & II & I & I & II & I \\
\hline Colênquima subepidérmico & - & + & - & - & - & + \\
\hline Laticíferos & + & - & + & + & + & + \\
\hline Monocristais prismáticos & - & + & + & - & - & + \\
\hline Tricoma tector do tipo “malpighiáceo" & - & + & + & + & + & + \\
\hline Tricoma tector simples & - & - & - & - & - & - \\
\hline Folha hipoestomática & + & - & + & + & + & + \\
\hline Folhas anfiestomática & - & + & - & - & - & - \\
\hline Pecíolo circular em seção transversal & - & - & - & - & - & - \\
\hline Pecíolo plano-convexo em seção transversal & - & + & - & - & - & - \\
\hline Pecíolo côncavo-convexo em seção transversal & + & - & + & + & + & + \\
\hline Sistema vascular do pecíolo em arco aberto & + & - & - & - & - & - \\
\hline Sistema vascular do pecíolo plano-convexo & - & - & + & + & + & - \\
\hline Sistema vascular do pecíolo côncavo-convexo & - & + & - & - & - & +
\end{tabular}




\begin{tabular}{l|c|c|c|c|c|c} 
Bainha de esclerênquima ao redor dos feixes vasculares & + & + & - & + & + & + \\
\hline Folha glabra & + & - & - & - & - & - \\
\hline Folha glabra na face adaxial e com tricomas na face abaxial & - & - & - & - & + & - \\
\hline Folha glabra na face abaxial e com tricomas na face adaxial & - & - & + & - & - & - \\
\hline Folha com tricomas em ambas as faces & - & + & - & + & - & + \\
\hline Bordo fletido & - & + & - & + & - & - \\
\hline Bordo levemente fletido & + & - & + & - & - & - \\
\hline Bordo fortemente fletido & - & - & - & - & - & - \\
\hline Bordo não fletido & - & - & - & - & + & +
\end{tabular}

Legenda: 1a. Chrysophyllum gonocarpum (Mart. \& Eichler ex Miq.) Engl. (Bahia); 1b. Chrysophyllum gonocarpum (Mart. \& Eichler ex Miq.) Engl. (Pernambuco) 2. Chrysophyllum marginatum (Hook. \& Arn.) Radlk;; 3. Chrysophyllum rufum mart.; 4a. Chrysophyllum splendens Spreng. (Bahia); 4b. Chrysophyllum splendens spreng. (Pernambuco) $(+)=$ presente; $(-)=$ ausente.

\section{CONSIDERAÇÕES FINAIS (ou Conclusão)}

A partir destes estudos foi possível realizar o levantamento das características anatômicas das folhas de quatro espécies de Chrysophyllum L., ocorrentes no semiárido, e permitiu a identificação de características que são decisivas na distinção das espécies. Algumas características podem ser consideradas diagnósticas para delimitar espécies como, por exemplo a variação no tipo de estômato, a conformação do sistema vascular, a localização dos estômatos nas faces da folha, a presença ou ausência de tricomas, caracterizando a folha como glabra ou não. Todas as características observadas no presente estudo estão de acordo com a bibliografia consultada, para a família, porém devido à importância da madeira das espécies de Sapotaceae, carecem estudos da anatomia foliar do grupo. Acredita-se na investigação de caracteres micromorfológicos que possam colaborar com estudos de outra natureza, constituindo mais uma ferramenta para a compreensão e circunscrição das espécies estudadas. Ressaltando que o trabalho desenvolvido é pioneiro nessa área.

\section{REFERENCIAS}

APPEZZATO-DA-GLÓRIA, B.; CARMELLO-GUERREIRO, S. M. 2003. Anatomia Vegetal. Viçosa: Editora UFV. 438p.

APPEZZATO-DA-GLÓRIA, B.; CARMELLO-GUERREIRO, S. M. 2013. Anatomia Vegetal. $3^{\text {a }}$ edição: Editora UFV.404p.

CARNEIRO, C. E.; ALVES-ARAUJO, A.; ALMEIDA JR., E. B.; TERRA-ARAUJO, M. H. 2017 Sapotaceae in Lista de Espécies da Flora do Brasil. Jardim Botânico do Rio de Janeiro. Disponível em: <http://floradobrasil.jbrj.gov.br/jabot/floradobrasil/FB217>.

GENTRY, A.H. 1993. A field guide to the families and genera of woody plants of northeast South America. Washington, D.C.: Conservation International.

JOHANSEN, D.A. 1940. Plant Microtechnique. New York, Mc Graw Hill Book

KRAUS, J. E. \& ARDUIN, M. 1997. Manual básico de métodos em morfologia vegetal. Rio de Janeiro, EDUR.

MACÊDO, N. A. 1997. Manual de técnicas em histologia vegetal. Feira de Santana: Universidade Estadual de Feira de Santana, 98p.

METCALFE, C.R. \& CHALK, L. 1972. Anatomy of the dicotyledons. Vol I. Oxford: Oxford Claredon Press.

METCALFE, C.R. \& CHALK, L. 1979. Anatomy of the dicotyledons. Vol I. Systematic antomy of the leaf and stem, ed.2. Oxford: Oxford Claredon Press.

PENNINGTON, T.D. 1990. Sapotaceae. Flora Neotropica Monograph 52. New York: The New York Botanical Garden.

SOLEREDER, H. 1908. Systematic anatomy of the dicotyledons. Oxford, University Press. 